\title{
Integration Management of Western Acquisitions in Japan
}

\author{
Fabian J. Froese $^{\mathrm{a}}$ and Leif E. Goeritz ${ }^{\mathrm{b}}$ \\ ${ }^{a}$ Graduate School of Asia Pacific, Waseda University, Nishi-Waseda Bldg. 7F, 1-21-1 Nishi- \\ Waseda, Shinjuku-ku, Tokyo 169-0051, Japan. \\ E-mail: fabian@fuji.waseda.jp \\ ${ }^{\mathrm{b}}$ German Centre for Industry and Trade Beijing Co. Ltd, Landmark Tower 2, Unit 1111, 8 North \\ Dongsanhuan Road, 100004 Beijing, People's Republic of China.
}

In recent years, Japan has seen a sharp increase in foreign cross-border merger and acquisition (M\&A) transactions. Among the larger cross-border M\&A transactions in Japan, a few multinational companies are already struggling with their acquisitions. In this study, we systematically analyzed and compared the unsuccessful DaimlerChrysler-Mitsubishi acquisition with the successful RenaultNissan acquisition. We collected secondary data and conducted interviews with both Japanese and foreign managers. Despite some similar starting conditions, these acquisitions developed widely divergent outcomes. In this study, we have focused on post-acquisition integration and separated it into human integration and organizational integration. Findings indicate that human and organizational integration are strongly interwoven in Japan, with human integration being a necessary prerequisite for organizational integration. These findings highlight the importance of the human factor in the success of acquisitions. Active communication, participation, assertive leadership, commitment and the creation of a sense of urgency have been found to facilitate human integration. With regard to organizational integration, the autonomy of the integration management and independence from any keiretsu network have been identified as important factors. Asian Business \& Management (2007) 6, 95-114. doi:10.1057/palgrave.abm.9200208

Keywords: mergers and acquisitions; human integration; organizational integration; employee resistance; Japan

\section{Introduction}

Historically, Japan has received significantly less cross-border foreign direct investment (FDI) than other developed countries (Eurostat, 1999; Fukao and Murakami, 2005). However, in recent years, intensified globalization and deregulation has led to a sharp increase in cross-border M\&A transactions in Japan (Moerke, 2003; Fukao and Murakami, 2005; UNCTAD, 2005). Press, 
media, consultants and Japanese managers seem extremely optimistic that the flow of cross-border M\&A will continue to expand (Financial Times, 2005; www.eiu.com/MA_Japan). During this process, foreign companies are expected to help restructure distressed companies (Asaba, 2005). By doing so, foreign companies might play a role in the currently discussed process of converging management practices.

Despite general enthusiasm, the performance of companies following M\&A transactions has been rather disappointing. In a study of 1,700 companies in the USA, Europe and Japan, Harding and Rovit (2004) quote a failure rate of 70 per cent. Among the larger cross-border M\&A in Japan, a few multinational companies are already struggling with their acquisitions. In this study, we analyze one of these unsuccessful acquisitions, namely DaimlerChryslerMitsubishi, and compare it with the successful Renault-Nissan acquisition. In both cases a Western automobile company, French and German-American respectively, acquired a controlling stake in a distressed Japanese automobile company.

Despite several similar starting conditions, these two acquisitions developed widely divergent outcomes that suggest differences in post-acquisition integration processes. Other authors familiar with the Renault-Nissan case have also argued that success lies more in post-acquisition management than in strategic, legal or financial issues (Takarabe, 2002; Magee, 2003; Ghosn and Ries, 2005). Therefore, this study focuses on analyzing the post-acquisition integration management process.

Post-acquisition integration processes have often been described as the decisive factor in M\&A success (Haspeslagh and Jemison, 1991; Pablo, 1994). Following Birkinshaw et al. (2000), we divided the post-acquisition integration process into organizational integration (task integration) and human integration (employee resistance). Whereas organizational integration deals with the operational integration of the firms, human integration analyzes the (mostly negative) reactions of employees towards $M \& A$ integration, and methods of managing these reactions.

The majority of previous studies have tried to single out and analyze only one factor within one of these two categories. As a result, findings have been mixed and sometimes even contradictory. Few studies have tried to integrate various aspects to reach a better understanding of the M\&A process (eg Larsson and Finkelstein, 1999; Very and Schweiger, 2001). Birkinshaw et al. (2000) made a first attempt at a more comprehensive analysis by investigating the role of organizational and human integration in acquisitions. However, their theory was based on only three successful acquisition cases, of Swedish companies in Europe and America.

This study is unique in three aspects. First, we hope to shed some light on the under-investigated area of post-acquisition management of cross-border M\&A 
in Japan. Second, the systematic comparison between a successful and an unsuccessful acquisition might lead to new insights unavailable when only looking at successful cases. Third, we hope to give some further insights on the relationship between human and organizational integration.

\section{Human Integration}

Research in the area of organizational behavior, psychology and human resource management focusing on behavioral implications of M\&A activity has been frequently grouped under the terms 'human integration' or 'employee reactions' (Larsson and Finkelstein, 1999; Birkinshaw et al., 2000).

Previous studies have generally found that employees react negatively to M\&A. M\&A activity often introduces significant change. In order to reduce cost and achieve synergies, companies usually replace existing managers, reduce the workforce and change existing management practices (Lubatkin et al., 1999). Consequently, the remaining employees tend to react to these changes with increased stress, tension and resistance (Buono and Bowditch, 1989). These dysfunctions have been associated with increased turnover of key people, diminished productivity and increased absenteeism. This harmful cycle, in turn, negatively influences the financial performance of the company (Greenwood et al., 1994; Larsson and Finkelstein, 1999).

Researchers have identified numerous reasons for employee resistance. First, a general scepticism or fear after the announcement of an M\&A, also known as the 'merger syndrome', results in distrust, tension and hostility between employees and senior management (Blake and Mouton, 1985; Marks and Mirvis, 1986). Even if only very few changes are to be implemented, M\&A activity has a destabilizing effect on the involved employees (Nikandrou et al., 2000). Second, differences in management styles have been found to be negatively correlated with M\&A success (Datta, 1991). Third, cultural issues, both at organizational and national level, have been identified as a main success factor (Cartwright and Cooper, 1993; Morosoni et al., 1998; Amano and Suzuki, 2002). While the majority of scholars agree that organizational cultural fit positively influences integration outcomes (eg Cartwright and Cooper, 1993), they have found mixed and even contradictory results on the effects of national cultural fit (Olie, 1994; Morosoni et al., 1998). Barkema et al. (1996) argue that cross-border M\&A might be more difficult, since companies have to engage in a double-layered acculturation, that is both organizational and national cultural integration.

Scholars and practitioners assume that the negative effects mentioned above can be mitigated by taking appropriate measures during the integration process. Appropriate communication and information have been widely accepted as factors for reducing stress among employees and supporting 
human integration (eg Schweiger and Denisi, 1991; Mikami, 2002). Schweiger and Denisi suggest that a realistic merger preview and a program of straightforward communication with employees can reduce stress and decrease dysfunction.

Discussion of participation - giving employees the opportunity to participate in the integration process - has resulted in some controversy. Shrivastava (1986) and Cartwright and Cooper (1993) argue that participation increases the acceptance of change and decreases the probability of resistance among employees of the acquired company. This facilitates human integration. On the other hand, Piske (2002), in an empirical study on cross-border M\&A in Poland, found that participation had no significant effect.

Another influential factor recently discussed in the context of M\&A is leadership. Sitkin and Pablo (2005) define leadership along six dimensions: personal, relational, contextual, inspirational, supportive and stewardship. All of these have to be carefully balanced to allow for smooth integration. Furthermore, the composition of the top management should be announced as soon as possible to avoid a leadership vacuum (Marks and Mirvis, 1986).

\section{Organizational Integration}

The organizational integration phase requires managers to integrate the companies in order to realize anticipated synergy effects, such as reduced cost per unit or increased income. Organizational integration can be defined as the degree of interaction and coordination between the two joining companies (see Larsson and Finkelstein, 1999). Successful integration enables organizational learning between the companies that might result in superior performance (Bresman et al., 1999; Pothukuchi et al., 2002).

Several factors influencing the success of organizational integration can be found in the literature. The level of integration has been highly investigated, though results have been mixed. Most of these studies distinguish between high and low levels of integration (eg Haspeslagh and Jemison, 1991). Managers of the acquiring company can initiate actions in order to absorb the new company fully into the existing one (high-level integration) or may only loosely place the new company under its umbrella, without making any significant changes (lowlevel integration), or effect any level of integration in between these two extremes. When Datta (1991) investigated the relationship between organizational fit and M\&A performance using level of integration as a moderator, he found no correlation. On the other hand, Larsson and Finkelstein (1999) and Piske (2002) found that the higher the level of integration, the higher the realization of synergy.

Although management consultants frequently quote speed of integration as a main success factor for post-acquisition integration, evidence from academia 
has not been able to support this idea (Angwin, 2004). Practitioners emphasize that employees are more willing to accept changes at the beginning of the integration process; hence, managers should take advantage of this momentum. On the other hand, managers need considerable time to understand the business of both companies and to develop plans for combining the companies, rather than adopting a 'let's do it' approach.

\section{Interplay Between Organizational and Human Integration}

Organizational and human integration have been described as two distinct concepts (Blake and Mouton, 1985; Birkinshaw et al., 2000). Birkinshaw et al. acknowledge that these two constructs are not independent and that enhanced human integration might ease capability transfer and resource sharing. Nevertheless, they cite Buono and Bowditch's (1989) study of a merger between two American banks as an example where organizational integration was achieved without human integration, resulting in high levels of dissatisfaction among employees.

Birkinshaw et al.'s study is based on three cross-border acquisitions of European companies in Europe and North America. Acquisitions between Western and Asian companies might encompass even greater differences in management style and culture (eg Hofstede, 2001). Japan and most Asian countries, in contrast to Western countries, are described as high-context cultures where human relations are valued (Hall, 1976). This implies that human integration might be especially important in an Asian setting. In this study we are interested in understanding how human integration and organizational integration affect the success or failure of cross-border acquisitions. At the same time, we analyze the various factors that drive human and organizational integration.

\section{Research Methodology}

Although research on cross-border M\&A has received increased attention in recent years, very little research has been carried out on cross-border M\&A in Japan. Great socio-cultural differences and differences in management practices between the West and Japan have been widely discussed. Warwick and Osterson (1973) explicitly caution researchers about the pitfalls of simply transferring Western theories into foreign cultures. By the same token, Clark et al. (1999) criticize the prevalence of ethnocentrically biased survey studies and advocate, amongst other suggestions, more qualitative approaches.

Considering these concerns, and the exploratory nature of our research objectives, we chose a case study research design. Case studies are especially 
appropriate when one is answering the questions why or how (Yin, 1994). To address Geddes' (1990) critique that selecting only cases with a positive outcome might lead to false inferences, we deliberately chose two companies with similar preconditions, but divergent outcomes. This research design is based on J.S. Mill's theory of difference and allows the formulation of theories for success and failures (Eisenhardt, 1989). As suggested by Yin, we advanced our research question and identified potentially important constructs in the literature before collecting data. Based on previous research (Birkinshaw et al., 2000), we separated the integration process into human and organizational integration. For human integration, we identified communication, participation and leadership as potentially important factors; for organizational integration, we identified the factors of speed and level of integration. During interviews, observations and data analysis, we paid special attention to these factors, eg we prepared several questions regarding these factors for our interview guideline, but were also open to any emerging findings (Eisenhardt, 1989; Yin, 1994).

To get an initial understanding of the two cases, we conducted web-based database research (Google Scholar, NACSIS, ProQuest, Wiso-net, etc.). Whereas there is a large research literature on Renault-Nissan, there is little empirical research on DaimlerChrysler-Mitsubishi. Valuable information for Renault-Nissan was drawn especially from the books Turnaround (Magee, 2003), Shift (Ghosn and Ries, 2005) and Karurosu go-n ha Nissan wo ikani shitekaeta ka (How did Carlos Ghosn Change Nissan?) (Takarabe, 2002). As for DaimlerChrysler-Mitsubishi, aside from some brief articles and press releases, only an unpublished master's thesis at the University of St. Gallen (Wiechmann, 2004) is worth mentioning. These resources and the research literature on integration management of M\&A enabled us to design a guideline for our interviews.

M\&A is a very sensitive topic for the involved companies and their managers. Generally, it is difficult to obtain data in these situations, particularly when the M\&A has been perceived as a failure. All attempts to gain official access to the DaimlerChrysler headquarters in Stuttgart, despite having personal contacts with one of the senior managers, were to no avail. Owing to the extreme sensitivity of the situation, we refrained from taperecording these interviews. Nevertheless, in 2004 and 2005, we were able to conduct twelve interviews. At Renault-Nissan, we conducted two interviews with Japanese managers and three with non-Japanese managers. At DaimlerChrysler-Mitsubishi we talked to two Japanese and five German managers.

Interviews were semi-structured and lasted on average one hour. These semistructured interviews allowed us not only to re-evaluate our predefined constructs, but also gave interviewees enough room to contribute their own 
ideas, so that other important factors could emerge during these interviews. In addition to these interviews, we verified our findings with several external consultants and scholars to refine our discussion.

\section{Renault-Nissan vs DaimlerChrysler-Mitsubishi}

\section{Overview}

After two restructurings in the 1980s and 1990s, Renault, the second largest French automobile maker, returned to profitability in the mid-1990s. As a medium-sized car company, Renault was looking for a partner in order to remain competitive in the long term. Nissan, with its strong presence in Asia and America, offered Renault a great opportunity to pursue its global aspirations. At the start of the alliance, Nissan's fortunes were at crossroads. Nissan had suffered consecutive losses to such an extent that it needed a partner in order to survive. Renault was not the first choice for Nissan, however. In March 1999, after failed attempts to form alliances with domestic and major global firms, Nissan sold a 36.8 per cent stake to Renault for US\$5.4 billion. In line with its global strategy, Renault also took over Samsung's car division in South Korea.

Daimler Benz merged with Chrysler in 1998 in order to create a transcontinental automobile company. Juergen Schrempp, the ambitious CEO of DaimlerChrysler at that time, had the vision of creating a 'Welt AG' (World Inc.). To realize his vision, DaimlerChrysler needed to find a partner in Asia. After Honda rejected an earlier offer and internal objections prevented a partnership with Nissan, DaimlerChrysler decided to team up with Mitsubishi Motors, the last remaining Japanese car maker looking for an international partner. DaimlerChrysler expected the alliance to offer access to Asia as well as synergy in the subcompact car and small-size truck markets. Like other Japanese automobile makers, Mitsubishi Motors had suffered severely from unfavorable economic conditions. However, in contrast to Nissan, Mitsubishi was backed by the powerful Mitsubishi keiretsu (corporate grouping), which included the Bank of Tokyo Mitsubishi and Mitsubishi Heavy Industry. In March 2000, one year after Renault-Nissan, DaimlerChrysler announced it had paid approximately US\$2.5 billion for a 34 per cent stake in the Mitsubishi Motors Corporation.

Although both acquisitions have been labeled as strategic alliances, they resemble acquisitions more than alliances. According to Japanese corporate law, a company can be controlled if a stake of more than 33.3 per cent has been acquired. Both foreign car-makers acquired a stake larger than 33.3 per cent and appointed the top management. Furthermore, in the case of RenaultNissan, a formal alliance was not set up until three years later, on March 28, 
Table 1 Overview of the two acquisitions

\begin{tabular}{lll}
\hline & Renault-Nissan & DaimlerChrysler-Mitsubishi \\
\hline Headquarters of acquirer & France & Germany-USA \\
Acquired stake & 37 per cent, later increased & 34 per cent \\
& to 44 per cent & \\
Financial strength of acquirer & Medium & Medium to high \\
Financial situation of target & Distressed & Distressed \\
Motives of acquisition & Global expansion, acquiring & Global expansion, acquiring \\
& technologies & technologies \\
Outcome & Success & Failure, divestment \\
\hline
\end{tabular}

2002, and changes such as major layoffs of employees have taken place at Nissan, but not at Renault.

After two years, when human integration had been completed, Renault further extended the scope of its cooperation with Nissan and started to jointly develop new cars and build joint platforms. Profit targets were achieved ahead of schedule and Nissan boasted of the highest operating profit margin among all automobile companies. These very positive results induced Renault to increase its stake in Nissan to 44 per cent, while Nissan acquired a 15 per cent stake in Renault. In sharp contrast, conditions at DaimlerChrysler-Mitsubishi were worsening, and the situation finally escalated in 2004. After losses in 2003, partly due to a risky car loan program in the US that resulted in high loan default rates, DaimlerChrysler refused to participate in a capital increase in April 2004. A huge defect cover-up scandal, which dated back to almost a decade but wasn't revealed until June 2004, signaled the end of the partnership. DaimlerChrysler exited the partnership and, as part of the deal, acquired 85 per cent of Fuso, the truck and bus division of Mitsubishi. These two cases show roughly similar starting conditions, but resulted in very different outcomes (Table 1). In the following sections we will compare the differences in human and organizational integration between these two acquisitions.

\section{Human integration}

Both Renault and DaimlerChrysler brought their own managers to Japan and significantly reduced the size of the existing board of management. In May 1999, two months after the announcement of the acquisition, Renault executive Carlos Ghosn was appointed Chief Operating Officer, later President of Nissan, and subsequently as CEO of both Renault and Nissan concurrently. Prior to his Japan assignment, Ghosn had already gained experience in turnaround management in South and North America. His leadership style is participatory and characterized by well-defined objectives, expressed, for 
instance, through the 'Nissan Revival Plan', stating Nissan's mid-term goals. He enjoys near-celebrity status in Japan, as well as almost unlimited respect inside the company. 'He is the undisputed leader and we look up to him', as one Japanese manager noted.

In July 2000, four months after the acquisition announcement, DaimlerChrysler dispatched a team of managers, headed by Rolf Eckrodt, to turn around Mitsubishi. However, it took two years before Eckrodt finally became the official head of DaimlerChrysler-Mitsubishi. Although he is well-respected, he and the other DaimlerChrysler managers never received the full support of Mitsubishi employees. In contrast to Ghosn, Eckrodt and his team were criticized for lacking clear and well-defined goals. It was unclear what role Mitsubishi would play within DaimlerChrysler. One manager noted that Eckrodt was 'too soft' and sought consensus with the Mitsubishi managers instead of striving for more ambitious and sometimes painful cost-cutting measures. To make matters worse, Eckrodt's authority was challenged not only by Mitsubishi's top managers, and also lacked solid support from the Stuttgart headquarters.

At the beginning of the Renault-Nissan alliance, it was important to 'start building bridges' between Renault and Nissan, as one Renault manager pointed out. In June 1999, a committee was built to promote joint strategy and synergies between the two companies. This committee comprised the CEO of Renault, the CEO of Nissan, five VPs of Renault and five VPs of Nissan, and met on a monthly basis. In addition to this committee, Renault-Nissan established eleven cross-company teams, involving managers from various levels. Interaction not only between Renault and Nissan but also within Nissan, needed to be enforced in order to initiate changes. When Ghosn first inspected Nissan, he noticed that Nissan had a very hierarchical and divisional structure. But participation of employees from various divisions and functions was of the utmost importance in enhancing communication and collaboration between divisions. Therefore, Ghosn installed nine cross-functional teams, comprising employees from various divisions, functions and hierarchical levels, to implement changes in various functional areas, such as integration of IT systems. The results developed by these cross-company and cross-functional teams were, after approval by the top management, binding and executed. These teams enhanced participation and communication within the teams themselves, and also had a spill-over effect on other employees. RenaultNissan also supported the flow of information through various channels such as email, bulletins, the company magazine and videos.

In contrast to Renault, DaimlerChrysler relied mainly on their own managers to plan and execute changes. Although several small cross-company teams of line managers were established, no one was clearly delegated the responsibility for executing the findings of these projects. The only positive 
exception was the R\&D department, where collaboration between Daimler Chysler and Mitsubishi Motors took place. One highlight of this R\&D collaboration was the joint production of the small-sized cars 'smart for four' and 'Mitsubishi Colt'. While Mitsubishi managers were initially optimistic about learning from and cooperating with DaimlerChrysler managers, they were treated as 'junior' partners and not a single Japanese executive was involved in top management decisions. Like Nissan, Mitsubishi had a very inflexible divisional structure, but unlike Renault, DaimlerChrysler did little to enforce communication and collaboration between the divisions from the beginning. Only the division heads communicated with each other, but even they mainly reported to the CEO. Not until March 2002, when Eckrodt officially took the helm at Mitsubishi, did he emphasize the importance of joint decision-making and install various cross-functional teams. However, due to urgent profitability pressure and the need for quick results, these crossfunctional projects were not completed and sometimes even canceled, though they were already ready for implementation. Not just participation, but also communication was restricted, discouraging Mitsubishi employees. DaimlerChrysler had a 'target-specific information' policy in place, meaning that important information was mainly restricted to top-level management. Most Mitsubishi employees 'did not really know what was going on'. In another failed attempt to enhance participation and communication, DaimlerChryslerMitsubishi set up a series of formal meetings, comprising more than a dozen Mitsubishi managers. These meetings were perceived as highly inefficient, however, partly due to the large number of participants. In the end, most Mitsubishi managers were rather irritated by the meetings and did not communicate the received information to their subordinates as the DaimlerChrysler managers expected them to.

In addition to the pre-formulated constructs from the literature review, two new potentially relevant constructs emerged during the interviews: commitment and sense of urgency. At both companies, Japanese employees were not fully aware of their respective companies' serious situation. To create the sense of urgency necessary to initiate change, Ghosn announced to his employees the 'Nissan Revival Plan'. The plan consisted of three quantifiable goals:

- Return to profitability for the fiscal year 2000.

- Achieve a consolidated operating profit of 4.5 per cent of sales by the fiscal year 2002.

- Reduce net debt from $¥ 1.4$ trillion to less than $¥ 700$ billion by the fiscal year 2002.

To underline his commitment, Ghosn publicly announced that if any one of these three goals was not achieved, he and the whole top management would resign. This statement put not only himself but also the whole top management 
Table 2 Summary of human integration

\begin{tabular}{lll}
\hline & Renault-Nissan & DaimlerChrysler-Mitsubishi \\
\hline Leadership & Well-defined objectives; & Unclear objectives; \\
& Management in place after 2 months & $\begin{array}{l}\text { Clear management authority after } \\
\text { 2 years }\end{array}$ \\
Communication & Information flow at all levels & Often restricted to top level \\
Participation & Cross-company and cross- & Some task forces, but without \\
& functional groups initiated changes & execution \\
Sense of urgency & Created & Assumed, not actively created \\
Commitment & Commitment and accountability & Unclear \\
Human integration & Achieved & Not achieved \\
\hline
\end{tabular}

team under pressure to achieve the goals. Besides this symbolic statement, Ghosn also demanded accountability on a day-to-day basis from all managers, based on the practice of management by objectives.

While the Revival Plan is a cornerstone of Ghosn's successful restructuring of Nissan, the importance of creating a sense of urgency and commitment has been more often mentioned by interviewees at DaimlerChrysler-Mitsubishi, where both factors were lacking. Although DaimlerChrysler also claimed costcutting as its ultimate goal, they were unable to create the necessary sense of urgency. Instead of conducting benchmark studies and revealing the deficits at Mitsubishi, Eckrodt took a more consensual approach and falsely assumed that the Mitsubishi managers were all on the same page. However, Mitsubishi managers did not feel this sense of urgency, as they believed that the Mitsubishi keiretsu would bail them out if necessary. Attitudes like 'we can do it without them' or 'we do not really need them' still prevailed.

DaimlerChrysler managers criticized Mitsubishi senior managers' lack of commitment to implementing changes. As the Mitsubishi managers were not involved in decision-making, they were partly working towards different goals. DaimlerChrysler managers, on the other hand, were perceived as lacking commitment to the DaimlerChrysler-Mitsubishi alliance, and acting opportunistically in the interest of DaimlerChrysler and their personal careers. Furthermore, as many German managers were only on short-term contracts to Japan, they were perceived as temporary 'guests'. In short, Renault has achieved human integration, but DaimlerChrysler has not been able to do so (see Table 2).

\section{Organizational integration}

DaimlerChrysler was mainly interested in the technology of small-size trucks and small-size cars, hoping to combine this division with its loss-making 'smart 
car' division. Renault had a general interest in the superior engineering skills of Nissan. Both DaimlerChrysler and Renault intended to achieve a high degree of organizational integration and change in the acquired company in order to reduce costs and acquire technology from their partner.

The desired speed of integration was high at both companies. According to its shareholder-value-oriented corporate philosophy, DaimlerChrysler, as a German-American company, was driven to follow its primary goal and deliver results in the short term. In addition to shareholder pressure, Renault did not possess the financial resources to withstand continuous losses at Nissan. In the end, the speed and level of integration of these two acquisitions proceeded quite differently.

Renault learned superior engineering know-how from Nissan and in return restructured Nissan. One Nissan manager commented that 'they benefit from our superior technology and we benefit from their superior marketing and management practices - a good deal for both'. Renault-Nissan implemented drastic cost-reduction measures at Nissan: They closed five plants, reduced the workforce by 21,000 (almost 15 per cent of the total workforce worldwide), shifted production partially to the US and rationalized the supplier network. Until then, 'Nissan had been practically robbed' by their suppliers. Nissan sold its shares to its suppliers and terminated contracts with more than half of them in order to renegotiate better prices. Human resource and management practices were adapted to worldwide (American) standards. Furthermore, English was introduced as a second business language at Nissan. All these measures were introduced in a speedy fashion. As a result, Nissan returned to profitability within one year after acquisition, ahead of schedule, though it should be noted that the 'Nissan Revival Plan' was not announced, nor major changes implemented, until more than six months after acquisition.

DaimlerChrysler had similar severe changes in mind, but failed to realize them. Ironically, Eckrodt said in an interview with Business Week (2004), shortly before the divestment of Mitsubishi Motors was announced by the Stuttgart headquarters, that since Renault had executed various changes and restructuring measures, it would be easier for DaimlerChrysler to do the same at Mitsubishi. Other DaimlerChrysler managers in Japan were similarly optimistic at that time. When contrasting DaimlerChrysler-Mitsubishi with Renault-Nissan, three potential reasons for the failure of organizational integration were frequently mentioned during the interviews.

First and foremost, employee resistance - in other words, the lack of human integration - was most frequently cited as one of the main reasons. All DaimlerChrysler managers interviewed mentioned employee resistance or stubbornness as one of the main reasons for the failure. They were unable to break the resistance of employees and gain their support. Different communication styles further widened the gap. For instance, when a German 
manager gave an assignment to one of his Japanese subordinates, the subordinate would often reply 'yes', without actually taking any action. The Japanese managers perceived the predominantly German integration managers as a 'storm that will pass very quickly'. Instead of cooperating with the turnaround team, then, the Japanese managers partly ignored the decisions of German managers and a 'shadow board of (Mitsubishi) managers' continued to be in charge of the 'real' decision-making. Eckrodt and his team were unable to win sufficient support from these Mitsubishi managers.

Second, lack of autonomy on the part of DaimlerChrysler managers was often mentioned during the interviews. The DaimlerChrysler managers in Tokyo not only lacked support from Mitsubishi employees, but furthermore were not endowed with the necessary authority from their Stuttgart headquarters. To make matters worse, Eckrodt did not even have a direct reporting line to the DaimlerChrysler CEO in Stuttgart. This might be another reason why changes were much slower here than at Renault-Nissan. On the one hand, decisions should have been made quickly. On the other hand, all major decisions needed to be approved by the headquarters in Stuttgart. Japanese managers also became aware of this situation and sarcastically compared the German managers to 'marionettes' directed by the Stuttgart headquarters.

Third, the strong connection to a major Japanese keiretsu did not allow the reorganization of the supply network or the introduction of major changes. Despite announcing the dissolution of the suppliers' council of Mitsubishi, DaimlerChrysler-Mitsubishi continued to buy supplies within the keiretsu. Due to an outdated and decentralized procurement system, DaimlerChrysler managers were not the only ones who had difficulties controlling purchases. An update of the procurement system would have enabled DaimlerChryslerMitsubishi to reduce purchasing costs.

Initially, both Renault and DaimlerChrysler had ambitious plans to revive their Japanese partners. However, only Renault was able to achieve organizational integration as intended. Table 3 summarizes the various factors contributing to the success of organizational integration.

Table 3 Summary of organizational integration

\begin{tabular}{lll}
\hline & Renault-Nissan & DaimlerChrysler-Mitsubishi \\
\hline Intended level of integration & High & High \\
Speed & High & Intended to be high \\
Keiretsu & No & Strong keiretsu \\
Autonomy & Yes & Limited, decisions needed approval of \\
& & Headquarters \\
Employee resistance & Overcome & Persisted \\
Organizational integration & Achieved & Partly, insufficiently \\
\hline
\end{tabular}




\section{Discussion}

This study focuses on acquisitions between companies from very diverse cultural backgrounds. On the one hand, great cultural and managerial differences offer great chances to learn from each other and may result in superior performance (Morosoni et al., 1998). On the other hand, such acquisitions are extremely difficult to manage successfully and have a high potential for failure. The two case studies illustrate precisely this 'paradox' (Dodgson, 2000). While the Renault-Nissan acquisition exceeded initial expectations, the DaimlerChrysler-Mitsubishi acquisition failed.

In this study, we have separated the post-acquisition integration process into human integration and organizational integration (Larsson and Finkelstein, 1999; Birkinshaw et al., 2000). The Renault-Nissan case demonstrates how active communication, participation of employees, leadership, the creation of a sense of urgency and commitment facilitated human integration.

That communication and information positively influences integration (eg Schweiger and Denisi, 1991) has been confirmed by this study on acquisitions in Japan. Although DaimlerChrysler managers were aware of the importance of communication, Renault-Nissan probably performed better in three aspects. First, Renault-Nissan allowed an almost free flow of all information, in contrast to a partly restricted information policy at DaimlerChryslerMitsubishi. Second, Renault-Nissan tried to communicate as many successful steps as possible to their employees. For instance, in a video, Louis Schweitzer, then CEO of Renault, informed all employees of some achievements shortly after the alliance was announced. Third, since Renault-Nissan was better able to involve the Nissan managers, these managers were more motivated to communicate the relevant information to their subordinates and coworkers.

This third point also links communication to involvement or participation, which was frequently highlighted by the press and media as one of the main factors for Ghosn's success. While Piske (2002), in a study on cross-border acquisitions in Poland, an individualistic culture, did not find significant effects of participation, it is not surprising that people in a group-oriented culture like Japan (Davies and Ikeno, 2002) value participation highly. DaimlerChrysler tried to imitate Renault-Nissan's cross-company and cross-divisional project teams. However, these attempts failed, because projects were sometimes not fully carried out and usually not implemented.

Another problem during the integration process was leadership. Unlike Ghosn, Eckrodt never managed to receive full support from the Japanese managers and employees. A vertical society like Japan is characterized by sempai-kohai (senior-junior) relationships (Davies and Ikeno, 2002), where subordinates expect guidance from their superiors. However, Eckrodt struggled to occupy a position as the undisputed leader and, moreover, could 
not communicate well-defined and sometimes painful objectives to the Mitsubishi managers.

Our case-study research design, and selection of two cases with similar starting points, but different outcomes, not only allows us to sharpen our understanding of the effects of communication, participation and leadership but also reveal how a sense of urgency and commitment are potentially relevant factors in the integration process of acquisitions in Japan.

While change agents such as Kotter (1995) postulate that creating a sense of urgency is one of the first steps in initiating change, this factor seems especially important in Japan. Most Japanese employees were not fully aware of the threatening situation, since top managers tended to hide negative news. For example, Mitsubishi top managers were able to cover up a defect scandal for over a decade. Besides, Mitsubishi Motors is embodied within a powerful keiretsu and Mitsubishi managers believed that it would step in if necessary. In light of this, it is not surprising that some Japanese employees were not fully aware of the serious situation and did not see the need for necessary changes. Had this taken place in a Western context, Mitsubishi might have gone bankrupt after the divestment, as one external consultant noted. Ghosn expressed this sense of urgency through the 'Nissan Revival Plan'.

In contrast to Renault, DaimlerChrysler's commitment seemed questionable. These doubts were proven when DaimlerChrysler - to the surprise of Mitsubishi - decided to exit the partnership due to unexpected high losses. Japanese companies usually have a long-term rather than short-term focus (Aoki, 1990; Odagiri, 1992) and are therefore not as threatened as American managers by short-term losses. Commitment in terms of accountability was important for Ghosn at not only the company but also the personal level. Ghosn expressed his first mid-term objectives through the 'Nissan Revival Plan' and offered to resign if these objectives were not met. Certainly, one might argue that this was a symbolic gesture and that Ghosn, after studying Nissan's finances, knew before the announcement that achieving these goals was within reach. Nevertheless, it seems to have had the intended impact on employees. Moreover, Ghosn also made his managers accountable for their actions.

In terms of organizational integration, both Renault-Nissan and DaimlerChrysler-Mitsubishi quickly intended to introduce major changes. However, DaimlerChrysler was unable to do so. Lacking decision-making autonomy and entangled in a keiretsu network hindered Mitsubishi's organizational integration. Moerke (2002) argues that dismantling the keiretsu is an important measure for reducing cost. Autonomy is a rather new topic in the context of M\&A, but has been frequently discussed in the context of foreign subsidiaries (eg Ahmad, 2002). The findings in this study suggest that autonomy in decision-making is important for the integration management team. 
In addition, employee resistance - in other words, failed human integration - can be seen as the main reason why organizational integration was not achieved. Unlike Birkinshaw et al. (2000) and Buono and Bowditch (1989), the findings of this study indicate that human integration is a prerequisite for organizational integration. Without human integration, only limited organizational integration can be achieved. Organizational and human integration cannot be separated from each other in an Asian context. Scholars have frequently noted that building trust and relationships is of the utmost importance when engaging in business with Asian counterparts (eg Oikawa and Tanner, 1992; Cullen et al., 1996). Business and human relations might be separate in a Western context, as implicitly stated by Birkinshaw et al. (2000), but in an Asian context these concepts seem to be strongly interwoven. Moreover, in collective societies, outsiders might face hostility or simply be ignored (eg Nakane, 1970). For example, Japanese managers at Mitsubishi perceived German managers as guests or outsiders. Therefore, it is not surprising that Japanese managers only grudgingly accepted the changes they imposed. On the other hand, once accepted as an insider and as a leader, it is much easier to implement changes.

As the example of Renault-Nissan demonstrates, foreign investors are able to change existing business structures, despite cultural differences (eg Fukao and Murakami, 2005). Ghosn was able to not only successfully restructure Nissan but also initiate a new round of cost reductions in the whole industry. The outcome of the Mitsubishi acquisition was entirely different. Shareholder value was decreased at DaimlerChrysler; furthermore, the press and media reacted with outrage to the divestment, and the company's image in Japan had been severely damaged.

Following the evidence of this study, and inspired by Quah and Young (2005), we suggest a stage model for post-acquisition integration management (see Figure 1). The first stage deals with human integration and the various

\begin{tabular}{l|ll|}
\multicolumn{1}{c}{} & \multicolumn{2}{c}{ Human Integration } \\
\cline { 2 - 3 } Goals & - & Reduce stress \\
& - & Gain trust \\
- & Retain core people \\
\hline \multirow{4}{*}{ Relevant } & - & Participation \\
Factors & - & Leadership \\
& - & Sense of urgency \\
& - & Commitment \\
\hline
\end{tabular}

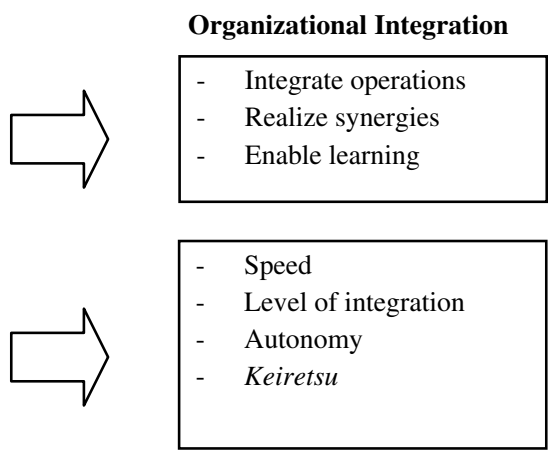

Figure 1 Stage model of integration management. 
Intensity/Relevance

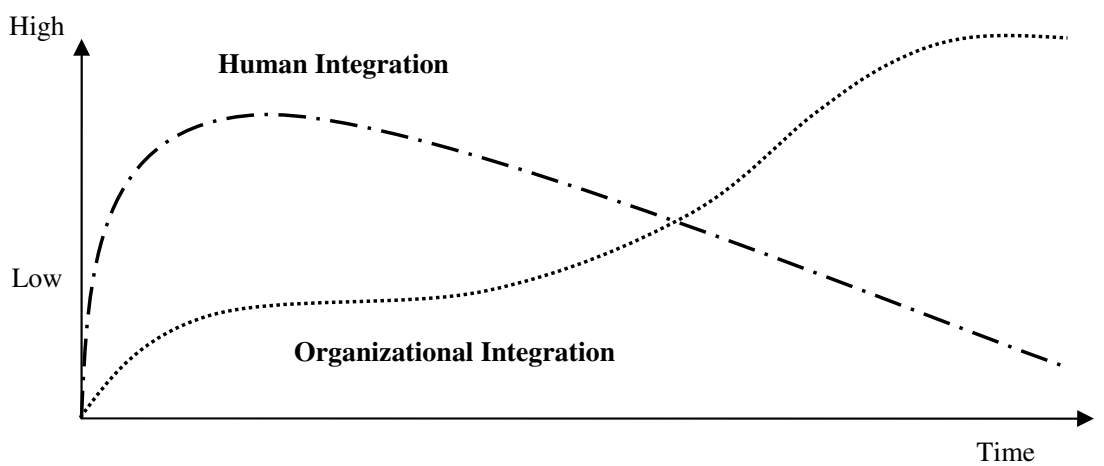

Figure 2 Relationship between human and organizational integration.

factors that facilitate the success of human integration. During the second stage, organizational integration can be fully realized.

We chose this stage model to highlight the importance of human integration or 'soft' factors (Cartwright and Cooper, 1992; Nikandrou et al., 2000). This stage model conveys the notion that human integration is more important in the early stages in facilitating organizational integration. Later, when human integration is achieved, organizational integration can be fully implemented. Figure 2 illustrates these ideas. This two-stage model does not imply that human integration must necessarily precede organizational integration. It is possible for both human and organizational integration to take place simultaneously from the beginning. For example, early in the integration process, defining authority, reporting lines and accountability as part of the organizational integration between the two companies and within the acquired company is necessary to facilitate human integration.

To be sure, our study is based on an analysis of only two acquisition cases between Western and Japanese companies. Therefore, the opportunities for generalization are limited. Nevertheless, according to the logic of J.S. Mill's method of difference, our selection of two cases with similar pre-conditions (control variables) but divergent outcomes might lend our findings more explanatory power than studies based solely on success cases (Geddes, 1990; Ebbinghaus, 2005). In this regard, the contribution of this research is two-fold. First, we provide an integrated model of integration management of crossborder acquisitions in Japan. Second, we explore various factors accounting for success or failure in integration management of cross-border acquisitions in Japan. Future studies could further investigate these factors, where a survey research design in particular could better clarify these relationships. 


\section{References}

Ahmad, A. (2002) 'Subsidiary autonomy: the case of multinational subsidiaries in Malaysia', Journal of International Business Studies 33(1): 183-191.

Amano, M. and Suzuki, R. (2002) Kigyo gappei to ibunka (Corporate Merger and Culture), Tokyo: Gakubunsha.

Angwin, D. (2004) 'Speed in M\&A integration: the first 100 days', European Management Journal 22(4): 418-430.

Aoki, M. (1990) 'Toward an economic model of the Japanese firm', Journal of Economic Literature 28: $1-27$.

Asaba, S. (2005) 'Do Foreign Shareholders Change Japanese Firms?', Paper presented at the 65th Academy of Management Annual Meeting; 5-10 August 2005; Hawaii, USA.

Barkema, H.G., Bell, J.H.J. and Pennings, J.M. (1996) 'Foreign entry, cultural barriers, and learning', Strategic Management Journal 17: 289-324.

Birkinshaw, J., Bresman, H. and Hakanson, L. (2000) 'Managing the post-acquisition integration process: how the human integration and task integration processes interact to foster value creation', Journal of Management Studies 37(3): 395-425.

Blake, R.R. and Mouton, J.S. (1985) 'How to achieve integration on the human side of the merger', Organization Dynamics 13: 769-782.

Bresman, H., Birkinshaw, J. and Nobel, R. (1999) 'Knowledge transfer in international acquisitions', Journal of International Business Studies 30(3): 439-462.

Buono, A.F. and Bowditch, J.L. (1989) The Human Side of Mergers and Acquisitions, San Francisco: Jossey-Bass.

Cartwright, S. and Cooper, C.L. (1992) Mergers and Acquisitions: The Human Factor, Oxford: Butterworth-Heinemann.

Cartwright, S. and Cooper, C.L. (1993) 'The role of cultural compatibility in successful organizational marriage', Management Executive 7: 57-70.

Clark, T., Gospel, H. and Montgomery, J. (1999) 'Running on the spot? A review of twenty years of research on the management of human resources in comparative and international perspective', International Journal of Human Resource Management 10(3): 520-544.

Cullen, J., Johnson, J.L., Sakano, T. and Takenouchi, H. (1996) 'Setting the stage for trust and strategic integration in Japanese-US cooperative alliances', Journal of International Business Studies 27(5): 981-1004.

Datta, D.K. (1991) 'Organizational fit and acquisition performance: effects of post-acquisition integration', Strategic Management Journal 12: 281-297.

Davies, R.J. and Ikeno, O. (eds.) (2002) The Japanese Mind, Boston: Tuttle.

Dodgson, M. (2000) The Management of Technological Innovation: An International and Strategic Approach, Oxford: Oxford University Press.

Ebbinghaus, B. (2005) 'When less is more: selection problems in large- $\mathrm{N}$ and small-N crossnational comparisons', International Sociology 20(2): 133-152.

Eisenhardt, K. (1989) 'Building theories from case study research', Academy of Management Review 14(4): 532-550.

Eurostat (1999) 'Value of Merger and Acquisitions Activity/Monetary Indicators', in DSI (ed.) International Statistical Yearbook: 1999, Rheinberg: DSI.

Financial Times (2005) 'Investing in Japan', Financial Times, 30 March.

Fukao, K. and Murakami, Y. (2005) 'Do foreign firms bring greater total factor productivity to Japan?' Journal of Asia Pacific Economy 10(2): 237-254.

Geddes, B. (1990) 'How the Cases You Choose Affect the Answers You Get: Selection Bias in Comparative Politics', in J. Stimson (ed.) Political Analysis, Ann Arbor: University of Michigan Press, pp. 131-150. 
Ghosn, C. and Ries, P. (2005) Shift: Inside Nissan's Historic Revival, New York: Doubleday.

Greenwood, R., Hinings, C.R. and Brown, J. (1994) 'Merging professional service firms', Organization Science 5: 239-257.

Hall, E.T. (1976) Beyond Culture, Garden City: Anchor.

Harding, D. and Rovit, S. (2004) Mastering the Merger: Four Critical Decisions That Make or Break the Deal, Boston: Harvard Business School.

Haspeslagh, P.C. and Jemison, D.B. (1991) Managing Acquisitions: Creating Value through Corporate Renewal, New York: Free Press.

Hofstede, G. (2001) Culture's Consequences: Comparing Values, Behaviors, Institutions, and Organizations Across Nations, Thousand Oaks: Sage.

Kotter, J. (1995) Leading Change, Cambridge, MA: Harvard Business School.

Larsson, R. and Finkelstein, S. (1999) 'Integrating strategic, organizational, and human resource perspectives on mergers and acquisitions: a case survey of synergy realization', Organization Science 10(1): 1-26.

Lubatkin, M., Schweiger, D. and Weber, Y. (1999) 'Top management turnover in related M\&As: an additional test of the theory of relative standing', Journal of Management 25(1): 55-73.

Magee, D. (2003) Turnaround: How Carlos Ghosn Rescued, Nissan, New York: Harper Business.

Marks, M.L. and Mirvis, P.M. (1986) 'The merger syndrome', Psychology Today 20(10): 36-42.

Mikami, M. (2002) Gappei Jinji (Human Resources after a Merger) Tokyo: Shoeisha.

Moerke, A. (2002) 'Quo Vadis Keiretsu? Structural Change in Japanese Inter-Firm Relations in the 1990s', in G. Foljanty-Jost (ed.) Japan in the 1990s, Muenster: Lit Verlag.

Moerke, A. (2003) 'M\&A in Japan - eine Bestandsaufnahme', in H. Conrad and R. Kroker (eds.) Deutschland und Japan: Mit Reformen zu neuer Dynamik, Cologne: Deutscher Instituts-Verlag, pp. 31-55.

Morosoni, P., Shane, S. and Singh, H. (1998) 'National cultural distance and cross-border acquisition performance', Journal of International Business Studies 29(1): 137-149.

Nakane, C. (1970) Japanese Society, Berkeley: University of California.

Nikandrou, I., Papalexandris, N. and Bourantas, D. (2000) 'Gaining employee trust after acquisition', Employee Relations 22(4): 334-355.

Odagiri, H. (1992) Growth Through Competition, Competition through Growth: Strategic Management and the Economy in Japan, Oxford: Clarendon Press.

Oikawa, N. and Tanner, J.F. (1992) 'The influence of Japanese culture on business relationships and negotiations', Journal of Services Marketing 6(3): 67-75.

Olie, R. (1994) 'Shades of culture and institutions in international mergers', Organization Studies 15(3): 381-405.

Pablo, A.L. (1994) 'Determinants of acquisition integration level: a decision-making perspective', Academy of Management Journal 37(4): 803-836.

Piske, R. (2002) 'German acquisitions in Poland: an empirical study on integration management and integration success', Human Resource Development International 5(3): 295-312.

Pothukuchi, V., Damanpour, F., Choi, J., Chen, C.C. and Park, S.H. (2002) 'National and organizational culture differences and international joint venture performance', Journal of International Business Studies 33(2): 243-265.

Quah, P. and Young, S. (2005) 'Post-acquisition management: a phase approach for cross-border M\&As', European Management Journal 23(1): 65-75.

Schweiger, D.M. and Denisi, A.S. (1991) 'Communication with employees following a merger: a longitudinal field experiment', Academy of Management Journal 34(1): 110-135.

Shrivastava, P. (1986) 'Post-merger integration', Journal of Business Strategy 1(7): 65-76.

Sitkin, S.B. and Pablo, A.L. (2005) 'The neglected importance of leadership in M\&As', in M.E. Mendenhall and G. Stahl (eds.) Mergers and Acquisitions: Managing Culture and Human Resources, Stanford: Stanford University Press. 
Takarabe, S. (2002) Karurosu go-n ha Nissan wo ikani shitekaeta ka (How did Carlos Ghosn Change Nissan?), Tokyo: PHP Bunko.

UNCTAD (2005) World Investment Report 2005: Transnational Corporations and the Internationalization of $R \& D$, New York: UNCTAD/Oxford University Press.

Very, P. and Schweiger, D. (2001) 'The acquisition process as a learning process: evidence from a study of critical problems and solutions in domestic and cross-border deals', Journal of World Business 36(1): 11-32.

Warwick, D.P. and Osterson, S. (eds.) (1973) Comparative Research Methods, Englewood Cliffs: Prentice-Hall.

Wiechmann, A. (2004) 'International strategic alliances in the automotive industry', Master's thesis, Department of International Management, University of St. Gallen.

Yin, R.K. (1994) Case Study Research: Design and Methods, London: Sage. 